\title{
Coral transplantation on a multilevel substrate of Artificial Patch Reefs: effect of fixing methods on the growth rate of two Acropora species
}

\author{
MUNASIK $^{1, \bullet}$, AGUS SABDONO ${ }^{1}$, AZELIA N. ASSYFA ${ }^{1}$, DIAH PERMATA WIJAYANTI ${ }^{1}$, SUGIYANTO ${ }^{2}$, \\ IRWANI ${ }^{1}$, RUDHI PRIBADI ${ }^{1}$ \\ ${ }^{1}$ Department of Marine Science, Faculty of Fisheries and Marine Science, Universitas Diponegoro. J1. Prof. Soedarto SH, Tembalang, Semarang 50275, \\ Central Java, Indonesia, Tel/fax.: +62-24-7474698, `email: munasik@lecturer.undip.ac.id \\ ${ }^{2}$ Department of Mechanical Engineering, Faculty of Engineering, Universitas Diponegoro. J1. Prof. Soedarto SH, Tembalang, Semarang 50275, Central \\ Java, Indonesia
}

Manuscript received: 21 January 2020. Revision accepted: 6 April 2020.

\begin{abstract}
Munasik, Sabdono A, Assyfa AN, Wijayanti DP, Sugiyanto, Irwani, Pribadi R. 2020. Coral transplantation on a multilevel substrate of Artificial Patch Reefs: effect of fixing methods on the growth rate of two Acropora species. Biodiversitas 21: $1816-1822$. Branching Acropora is generally used in coral transplantation to rehabilitate coral reefs. However, these corals are sensitive to environmental changes. Artificial Patch Reef (APR) is an artificial structure that provides a multilevel hard substrate. The purpose of the study was to investigate the effectiveness of the APR structure to facilitate the growth and survival of Acropora branching. Two species Acropora aspera and Acropora copiosa were transplanted vertically and horizontally on a modular concrete block in different levels of APR situated in the shallow reef of Panjang Island, Central Java. The results showed that the coral growth rate varied from 96.7 to $346.9 \mathrm{~cm}^{3} /$ month, while survival ranged from 30 to $100 \%$ after 8 months. Lower survival rate mostly was found in the upper level of APR. The statistical analyses showed that the growth rate of A. copiosa fragment was significantly higher than that of $A$. aspera $(\mathrm{p}<0.05)$. Moreover, there were also significant differences in the treatments of transplantation method $(\mathrm{p}<0.05)$ to enhance coral growth. However, multilevel substrates were not significantly influenced by coral growth. This study suggested that $A$. copiosa which has high-level complexity in branching pattern will be selected to apply in shallow reef rehabilitation with transplanted vertically.
\end{abstract}

Keywords: Acropora aspera, Acropora copiosa, artificial patch reef, coral transplant, Panjang Island

\section{INTRODUCTION}

Coral reef is one of an important ecosystem on earth, it is most complex and biodiverse ecosystem that provides the ecological services for humankind. Recently, coral reefs worldwide have been degrading by natural and manmade stress (Wilkinson 2000; Burke et al. 2011). Reef health has been declining apparently by limiting space for natural recruitment and change in physical environmental conditions (Done et al. 2010). Thus, coral reef rehabilitation is considered one of the major reef management strategies that coral reefs may not be able to recover naturally without human intervention.

To rehabilitate damage of natural reefs, artificial reefs and coral transplantation has been applied regardless of environmental condition, cause of decline, or goals. Coral transplantation generally applied by transplanted coral fragments on table cages in shallow water in order to cultivate coral fragments due to transferred and transplanted to rehabilitation reef areas (Heeger and Sotto 2000; Ammar 2013). It seems to be the most widely implemented for coral reef rehabilitation. Many studies dealing with reef rehabilitation by applied coral transplantation (Yap 2000, 2004; Epstein et al. 2001, 2003; Sabater and Yap 2002). Coral transplantation may contribute to enhance the coral population in the reef areas, although natural recovery indicated by coral recruitment (Edwards and Clark 1998; $\mathrm{Ng}$ et al. 2015). Coral transplantation method potentially has an impact on reef health by losing colonies from the donor area, reducing the growth of transplanted corals, reducing fecundity of transplant due to stress. Alternatively, artificial reefs are considered an efficient rehabilitation tool, it is a suitable method for protection of existing natural reefs, environmental, mitigation for damaged reef areas and shoreline protections (Meester et al. 2015; $\mathrm{Ng}$ et al. 2016). Artificial reefs are expected to increase in available substrates for reef organisms, provide structural complexity and natural recruitment. However, the application of these methods in Indonesia waters was apparently not successful, indicated by high mortality of coral fragments in coral transplantation and many artificial reefs that applied damage to natural reefs (Munasik 2009). In order to optimize reef rehabilitation, combining artificial reefs and coral transplantation is recommended (Abelson 2006; Ammar et al. 2013; Cummings et al. 2015).

Artificial Patch Reefs (APR) is an artificial structure which is applied to rehabilitate coral reef in order to develop shallow water habitat (Munasik et al. 2018). APR is a rehabilitation tool that is designed by multilevel substrates and applied the combination both of coral transplantation and artificial reefs. Acropora spp. is 
generally considered as a good for candidates for use in coral transplantation or population enhancement project due to their high growth rate and high survivorship of fragments (Lirman et al. 2010; Boch and Morse 2012; Mercado-Molina 2016; Schopmeyer et al. 2017). The application of APR with Acropora transplanted on their substrates is considered contributing to the local conservation of the small island reefs in the near future. In this study, two Acropora species were selected and applied to investigate the suitable method and species selection for reef rehabilitation. Multilevel substrates of APR may provide the hard substrate to facilitate fragment of coral grows in shallow turbid water. However, the information about the effect of multilevel substrates on survival and growth of transplanted corals is limited. This study aims to address the effectiveness of the APR structure to provide the multilevel substrate to facilitate the growth rate and survival of coral fragment.

\section{MATERIALS AND METHODS}

\section{Study area}

Acroporid corals are significantly important in the shallow reef of Panjang Island, Central Java however the population decline slightly due to the anthropogenic stressor (Munasik et al. 2012). Two species Acropora i.e. Acropora aspera and A. copiosa were known as limiting local population on the island. Colonies of A. aspera is common in the inner lagoon and the species was defined as a corymbose clump with short thick branches. Population of $A$. copiosa is generally found in front of the reef flat and colony was characterized as arborescent clumps of upright branches. Comparing to the previous species, Acropora copiosa have more complexity in branching patterns. Rehabilitation of coral reefs program was carried out in shallow reefs of Panjang Island Central Java by deployed 12 (twelve) artificial patch reefs (APR) from 2015 to 2018 at $3 \mathrm{~m}$ depth. In order to conduct a coral transplantation experiment, a unit of Artificial Patch Reef (APR) No. 12 was selected to perform the study of the effect of species and coral transplantation method in multilevel of substrates on growth of Acropora (Figure 1).

\section{Procedures}

Coral fragments were collected from donor site of two Acropora species in the inner lagoon and in front of the reef flat of Panjang Island. Fragments of A. aspera were collected by broken off small branches at random mother colonies while A. copiosa fragments were chisel off main branches of adult colonies randomly. The small branches of two species (average size was $12.57 \mathrm{~cm}^{3}$ ) were transferred into basket and then were transplanted on multilevel substrates of Artificial Patch Reefs (APR) which deployed in the eastern site of Panjang Island.
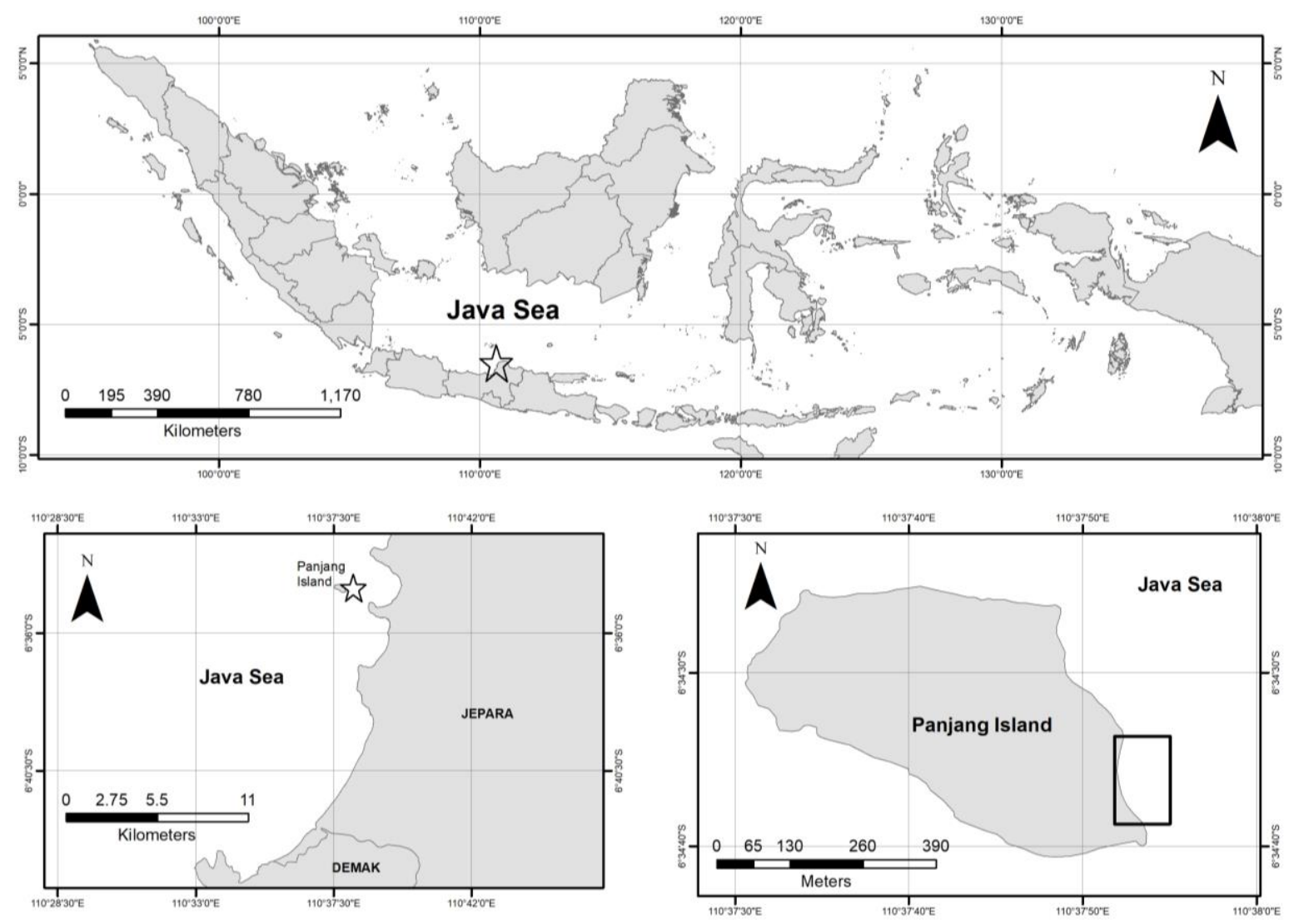

Figure 1. Study site of coral transplantation on Artificial Patch Reef at Panjang Island, Central Java, Indonesia (6³4’30” S; 110³7’44” E) 


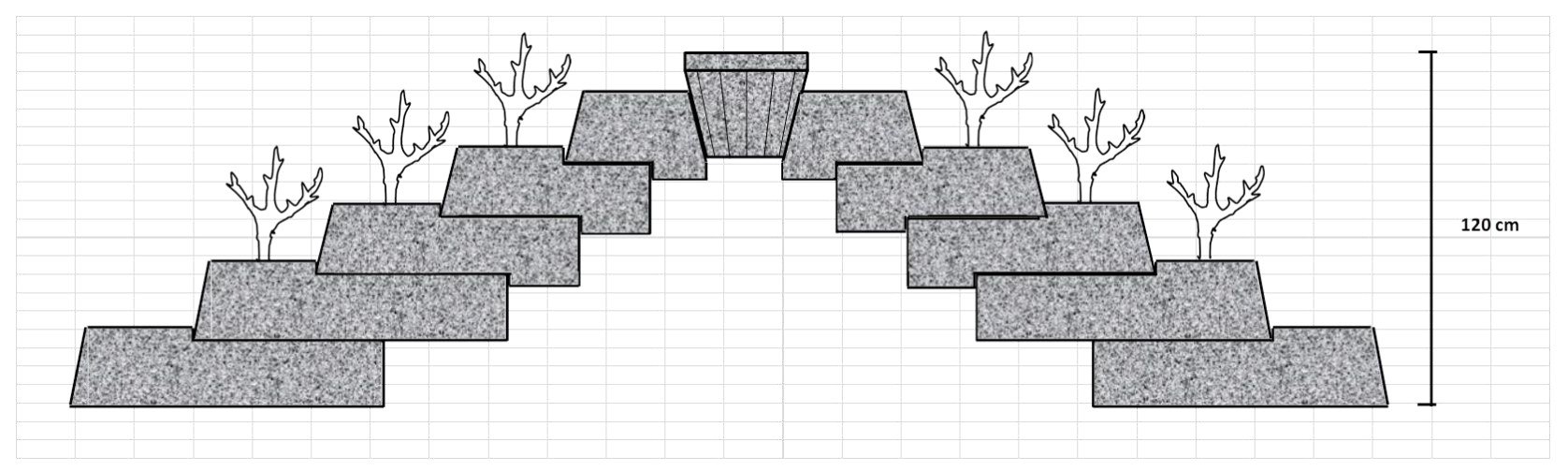

Figure 2. Layout of coral transplantation experiment, Acropora fragment transplanted on the multilevel: in upper, middle and lower of Artificial Patch Reef (APR)
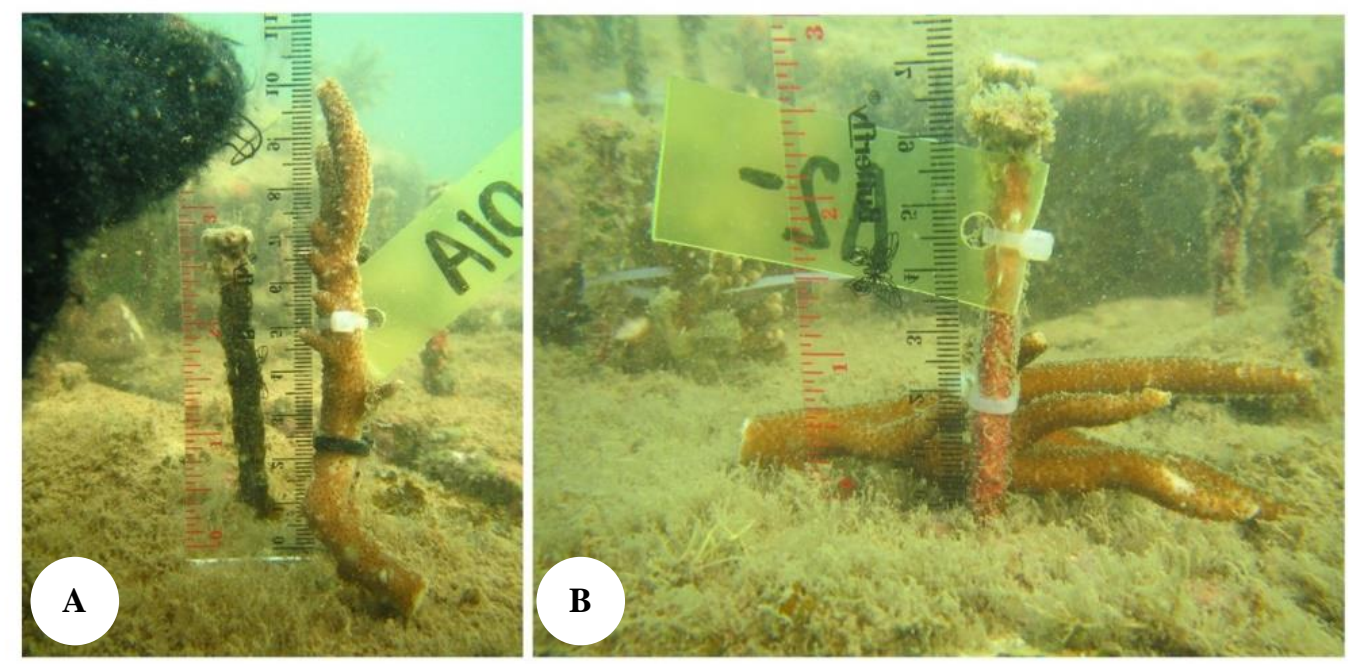

Figure 3. Fixing methods of coral fragments tied to nail by cable ties. A. vertically tixing method, B. horizontally fixing method

Artificial Patch Reefs (APR) is artificial reefs made by concrete blocks composed as modular circular structures in shape, constructed 5 (five) levels of substrates were deployed from small boats by SCUBA divers, and are suitable near natural reefs in shallow water. The total height of the multilevel APR structure is about $120 \mathrm{~cm}$ from the bottom of the sea, and the height of each level is $20 \mathrm{~cm}$. In this experiment, coral fragments were transplanted in the upper, middle, and lower level. Coral transplantation experiments were not applied at the top level to prevent physical damage in coral fragments. The experiments were also not implemented in the coral transplantation in the base of APR (level 5) since the surface of the substrate usually covering sediment due to resuspension (Figure 2). At the beginning of November 2018, 120 coral fragments were transplanted on three levels of APR by two fixation methods: vertically and horizontally orientation of the fragments fixing on the surface of substrates and tied to a paired of the nail using cable ties (Figure 3). Cable ties method of coral transplantation has been widely applied and effective technique for attaching Acropora fragments to artificial substrate (William and Miller 2010; Young et al. 2012). Coral fragment stabilization using cable ties was similarly effective to epoxy or cement methods (William and Miller 2010).

\section{Data analysis}

In order to investigate the growth rate of Acropora fragments, we used a measurement of corallum size in volume dimension (Buddemeier and Kinzie III 1976). The final measurement of volume (length, wide, and height) of the coral fragments were evaluated in late July 2019. The size of the fragments was measured by taking a picture using an underwater camera and putting the scale beside each the fragment (Mercado-Molina et al. 2016). The size measurement of the fragments was analyzed using image analyses of computer software, Image J. Volume of the fragment was determined by ecological volume (EV; de la Cruz et al. 2015), and its calculated following the cylindrical volume formula (Levy et al. 2010) as define, in equation (1)

$$
E V=\pi r^{2} h, \text { where } \quad r=\frac{(l+W)}{4}
$$


Growth rate $(G R)$ of the corals (Ecological Volume per month) was calculated using the formula (2)

$$
G r=[E V f-E V i] / m
$$

Where: Gr is the standardized growth rate, EVf and EVi are final and initial Ecological Volume and $\mathrm{m}$ is number of months elapsed.

Only the tagged coral fragments alive at 8 (eight) months post-transplantation were included in the growth rate determination.

In order to test the effect of different levels of transplant position, and different fixing methods of coral transplantation to the growth of two Acropora species, data of growth rate of the fragments were analyzed using two-way of variance (ANOVA, at $95 \%$ confidence level, $\mathrm{p}<0.05$ ).

\section{RESULTS AND DISCUSSION}

\section{Survival rate}

The survival rate of two Acropora species which transplanted on multilevel substrate was varied from 30 to $100 \%$, the average of the survival rate was $80 \%$. Both Acropora species which transplanted horizontally possess higher survivorship (average of survival rate was 95\%) than the fragments which transplanted vertically (average of survival rate was $85 \%$ ). The lower survival rate of the fragments was found in the upper level of substrates (varied from 30 to 50\%; Figure 4) which located on the top of APR, about $1 \mathrm{~m}$ from the bottom of the sea during low tide. Coral fragment of $A$. copiosa was more survive than A. aspera, indicated the lower survival rate coral fragment was found in A. aspera which transplanted vertically.

\section{Growth rate}

The growth rate of two Acropora species which transplanted on multilevel substrate of APR varied from
96.7 to $346.9 \mathrm{~cm}^{3} /$ month. The growth rate of Acropora fragments was significantly different among species, substrate levels and fixing method of transplantation $(p<0.05)$ after 8 months. The growth rate of two Acropora species on multilevel substrate of APR after 8 months demonstrated that there were no significant differences in species $A$ aspera. Whereas, there were significantly different on the A. copiosa growth that transplanted either in the upper and the middle levels or in the lower and in the middle levels $(p<0.05)$. However, there were no significantly different on the coral growth transplanted in the upper and in the lower levels (Table 1).

The growth rate of two Acropora species transplanted in different fixing methods (vertical vs. horizontal) demonstrated significantly different $(p<0.05$; Figure 5). Growth rate of the fragments which transplanted in vertical fixing method was higher than the horizontal method. The lowest growth rate was found in A. aspera which transplanted in horizontal fixing method, while the highest growth rate occurred in A. copiosa which transplanted in vertical fixing methods. Fragments of coral A. copiosa can grow optimally on all levels by both vertical and horizontal fixing methods of coral transplantation. Comparing the species, the growth of transplanted A. copiosa was higher than that of $A$. aspera due to the different branching patterns $(\mathrm{p}<0.05$; Figure 6).

Table 1. Growth rate $\left(\mathrm{cm}^{3} /\right.$ month) of transplanted two species of Acropora on multilevel substrate of APR after 8 months (November 2018-July 2019)

\begin{tabular}{lll}
\hline Level & A. aspera & A. copios $\boldsymbol{a}$ \\
\hline Upper & $130.05 \pm 47.16^{\mathrm{a}}$ & $293.00 \pm 76.23^{\mathrm{a}}$ \\
Middle & $178.75 \pm 34.17^{\mathrm{a}}$ & $152.05 \pm 95.11^{\mathrm{a}}$ \\
Lower & $202.75 \pm 44.74^{\mathrm{a}}$ & $333.30 \pm 64.21^{\mathrm{a}}$ \\
\hline
\end{tabular}

Note: All results are expressed as mean \pm SD. Values in each column which have the same letters are no significant different $(\mathrm{p}<0.05)$

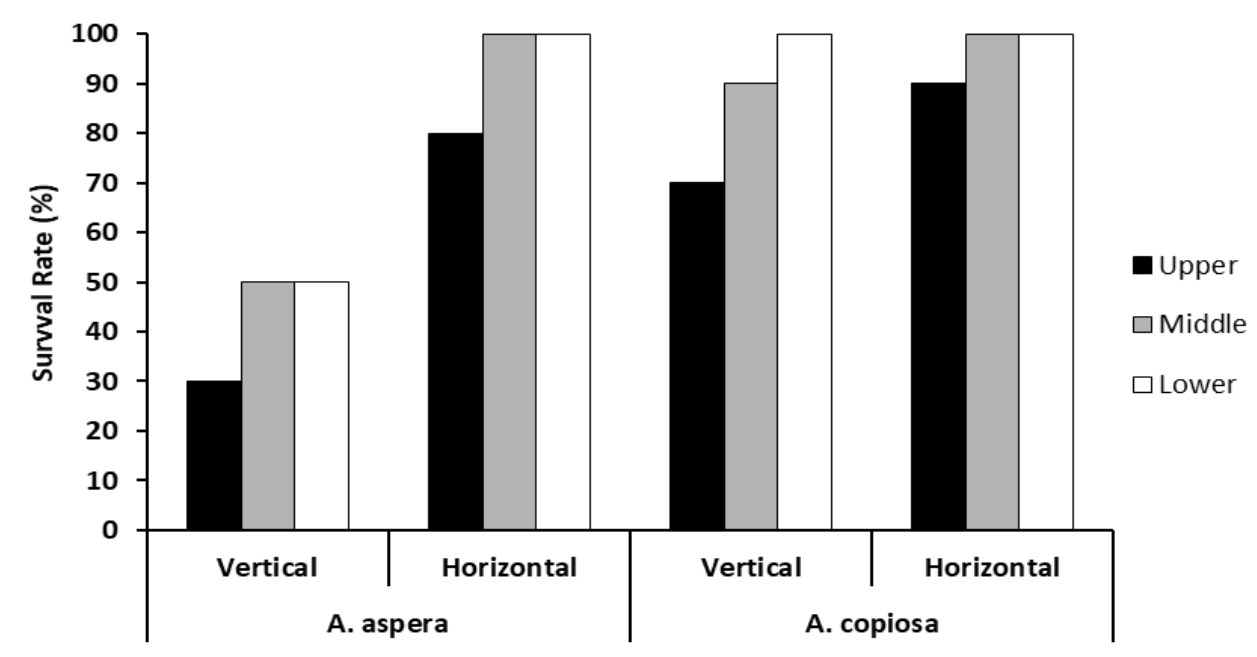

Figure 4. Survival rate (\%) of transplanted two Acropora species on multilevel substrate of APR after 8 months (November 2018-July 2019) 


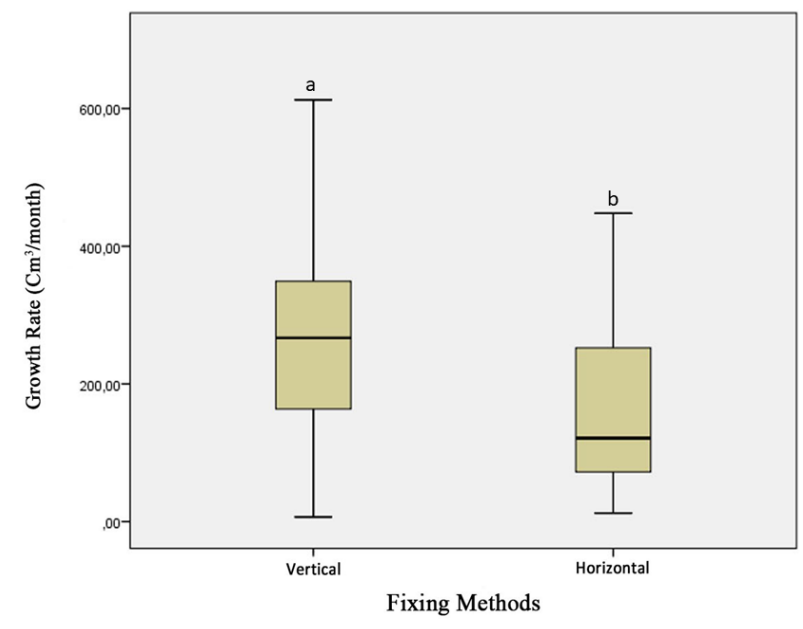

Figure 5. Growth rate $\left(\mathrm{cm}^{3} /\right.$ month) of transplanted two Acropora species on multilevel substrate of APR in different fixing method after 8 months, November 2018-July 2019 (Note: Letter in each bar which has different letters are significantly different, $p<0.05$ )

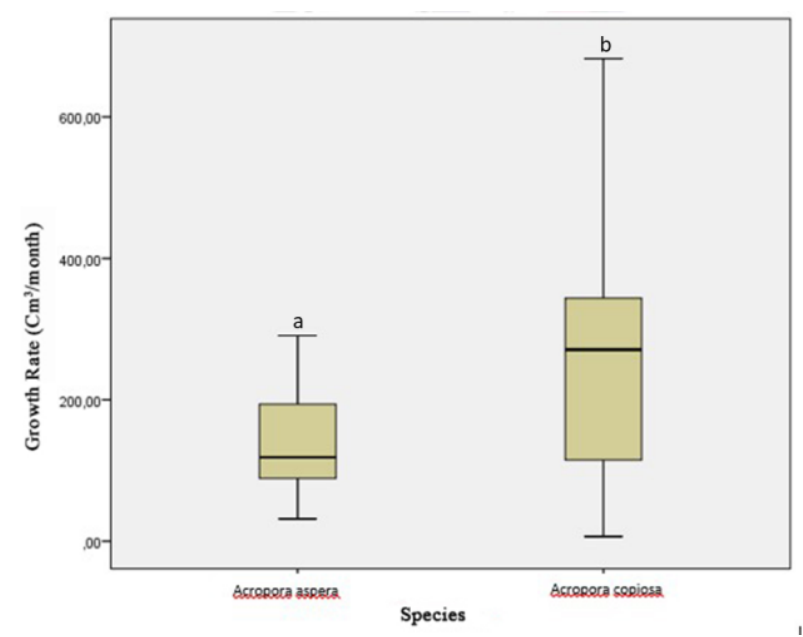

Figure 6. Comparison of growth rate $\left(\mathrm{cm}^{3} /\right.$ month) transplanted A. aspera and A. copiosa on multilevel substrate of APR after 8 months, November 2018-July 2019 (Note: Letter in each bar which has different letters are significantly different, $p<0.05$ )

\section{Discussion}

Lower survival rate during the experiment was revealed by $A$. aspera in all levels of substrate particularly in coral transplanted in fixing vertically. Coral fragments mortality was found in A. aspera which fixed in vertical orientation during the experiment. Lower survival rate of the coral fragments in vertically fixing method due to minimize of fragment surface attaching to the substrate may affecting the coral expend more energy in repairing the damage (Yap et al. 1992), consequently, the coral fragments died and then detached from the substrates. Additionally, lower survival rate of the coral fragments in the upper level may be caused by some of them lost by wave actions that occurred at the beginning of experiment, after fixed the coral fragments. Disadvantage of coral transplantation using directly fragment transplantation method on the substrates in shallow water is generally affected by algae competition, sediment accumulation and wave exposure (Young et al. 2012).

Acropora is one of the important coral in the shallow water and usually applied to coral transplantation (Heeger and Sotto 2000; Edwards 2010; Young et al. 2012). The coral was competent to grow fast, inversely they are also sensitive responding to the environment (Yap et al. 1992). Survival of the corals which have transplanted varied in different location and various in rehabilitation technic. The survival rate of Acropora in nubbin fix to the nursery table was $46 \%$ (Nithyanandan et al. 2018), while the high survival rate of the coral was found in Acropora hyacinthus, $83.3 \%$ (Bongiorni et al. 2011). In the present study, the survival rate of the Acropora is high due to the fragment stabilization using cable ties method and removing sediment accumulation caused by applying the

multilevel designed of substrate. Thus, application of Artificial Patch Reef (APR) in shallow reef rehabilitation can contribute to enhance the survival of Acropora fragments.

Some previous studies of coral transplantation revealed that the growth rate of Acropora was higher than that of other hermatypic corals. Bongiorni et al. (2011) reported that Acropora possesses relative growth ranged 66.9 to 83.3\%, while growth rate of Acropora which transplanted on the artificial reef dome-shaped was $1.07 \mathrm{~cm} /$ month (Muzaki et al. 2019), Acropora fragments fixed to the dead coral was $7.8 \mathrm{~cm} /$ year (Nithyanandan et al. 2018). This result showed that the growth rate of both Acropora which transplanted on multilevel substrate possesses a high growth rate. Presumably, the construction of multilevel APR can optimize coral growth by increasing light and preventing sediment coverage. The different branching pattern of the Acropora may affect to the growth of the corals, two Acropora shows a different level of complexity (Mercado-Monila et al. 2016) A. copiosa was more complex than A. aspera (Figure 7). Veron and StaffordSmith (2000) identified that A. copiosa was clumps of prostrate or upright branches irregular branching patterns with frequent sub-branches, while A. aspera which is defined as a corymbose clump with thick branches (Veron and Stafford-Smith 2000). The higher growth rate of vertically fixing method in Acropora copiosa indicated that vertical fixing of the fragments was suitable orientation of the natural growth form of the donor colony of Acropora (Okubo et al. 2005). This study suggests that multilevel APR using vertical fixation method of selected Acropora which has high-level complexity should be applied in future coral rehabilitation projects. 

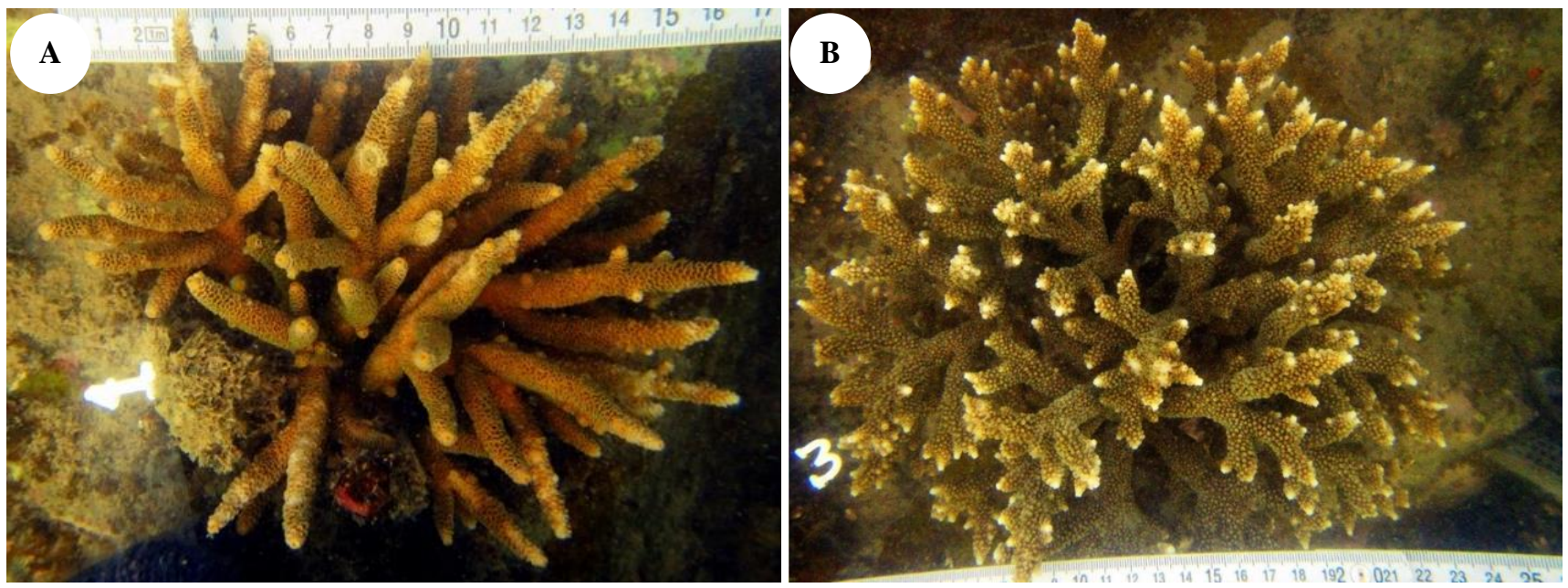

Figure 7. Transplanted of two species Acropora on multilevel substrate of APR after 8 months (A. horizontal fixing method of transplanted Acropora aspera; B. vertical fixing method of transplanted Acropora copiosa)

\section{ACKNOWLEDGEMENTS}

This study was supported by of Applied Research grant (No. 101-170/UN7.P4.3/PP/2018) from Ministry of Research and Technology, Higher Education to M, AS, and S. Part of the study was supported by research grant No. 1501-26/UN7.5.10/LT/2018 from Faculty of Fisheries and Marine Science, Diponegoro University to M, DPW, I, and RP. We thank Andy Ahmad for preparing coral measurement, Agus Susanto, and the staff of Marine Diving Club for field assistance and Tanjung Jati B CoalFired Power Plant to facilitate maintaining the artificial reefs. We appreciate two anonymous reviewers offered constructive comments to improve our manuscript.

\section{REFERENCES}

Abelson, Avigdor. 2006. Artificial reefs vs. coral transplantation as restoration tools for mitigating coral reef deterioration: benefits, concern and proposed guidelines. Bull Mar Sci 78 (1): 151-159.

Ammar MSA, El-gammal F, Nassar M, Belal A, Farag W, El-Mesiry G, El-Haddad K, Orabi A, Abdelreheem A, Shaaban A. 2013. Review: Current trends in coral transplantation-an approach to preserve biodiversity. Biodiversitas 14 (1): 43-53.

Bongiorni L, Giovanelli D, Rinkevich D, Pusceddu A, Chou LM, Donovaro R. 2011. First Step in the restoration of highly degrade coral reef (Singapore) by in situ coral intensive framings. Aquaculture 322: 191-200.

Boch CA, Morse ANC. 2012. Testing the effectiveness of direct propagation techniques for coral restoration of Acropora spp. Ecol Eng 40: 11-17.

Buddemeier RW, Kinzie RA III. 1976. Coral growth. Oceanogr Mar Biol Ann Rev 14: 183-225.

Burke L, Reytar K, Spalding M, Perry A 2011. Reefs at risk revisited. World Resources Institute, Washington D.C.

Cummings K, Zuke A, De Stasio B, Krumholz, J. 2015. Coral growth assessment on an established artificial reef in Antigua. Ecol Restor 33 (1): 90-95.

dela Cruz DW, Rinkevich B, Gomez ED, Yap HT. 2015. Assessing an abridged nursery phase for slow-growing corals used in coral restoration. Ecol Eng 84: 408-415.
Done TJ, De Vantier LM, Turak E, Fisk DA, Wakeford M, van Woesik R. 2010. Coral growth on three reefs: development of recovery benchmarks using a space for time approach. Coral Reefs 29: 815834.

Edwards AJ, Clark S. 1998. Coral transplantation: a useful management tool or misguided meddling? Mar Pollut Bull 37: 474-487.

Edwards AJ. 2010. Reef rehabilitation manual. The Coral Reef Targeted Research \& Capacity Building for Management Program, St Lucia, Australia.

Epstein N, Bak RPM, Rinkevich B. 2001. Strategies for gardening denuded coral reef areas: the applicability of using different types of coral material for reef restoration. Restor Ecol 9: 432-442.

Epstein N, Bak RPM, Rinkevich B. 2003. Applying forest restoration principles to coral reef rehabilitation. Aquat Conserv 13: 387-395.

Heeger T, Sotto F. 2000. Coral Farming: A Tool for Reef Rehabilitation and Community Ecotourism. German Ministry of Environment (BMU), German Technical Cooperation and Tropical Ecology program (GTZ-TÖB), Philippines.

Levy G, Shaish L, Haimb A, Rinkevich B. 2010. Mid-water rope nursery-Testing design and performance of a novel reef restoration instrument. Ecol Eng 36: 560-569.

Lirman D, Thyberg T, Herlan J, Hill C, Young-Lahiff C, Schopmeyer S, Huntington B, Santos R, Drury C. 2010. Propagation of the threatened staghorn coral Acropora cervicornis: methods to minimize the impacts of fragment collection and maximize production. Coral Reefs 29: 729-735.

Mercado-Molina AE, Ruiz-Diaz CP, Sabat AM. 2016. Branching dynamics of transplanted colonies of the threatened coral Acropora cervicornis: Morphogenesis, complexity, and modeling. J Exp Mar Biol Ecol 482: 134-141.

Meesters, EHWG, Smith SR, Becking LE. 2015. A review of coral reef restoration. Report to IMARES, WUR, Wageningen.

Munasik. 2009. The condition of artificial reefs made from concrete in several waters in Indonesia. Indonesian Coral Reef Symposium II, November, $20^{\text {th }}$ 2008, Jakarta. [Indonesian]

Munasik, Ambariyanto, Sabdono A, Diah Permata W, Radjasa OK, Pribadi, R. 2012. Spatial distribution of hard corals (Scleractinia) at Panjang Island, Central Java. Buletin Oseanografi Marina 1: 16-24 [Indonesian]

Munasik, Sugiyanto, Sugianto DN, Sabdono A. 2018. Reef Development on Artificial Patch Reefs in Shallow Water of Panjang Island, Central Java. IOP Conference Series: Earth Environ Sci 116: 012095. DOI: 10.1088/1755-1315/116/1/012095

Muzaki FK, Hanifa R, Akhwady R, Saptarini D, Buharianto. 2019. Short Communication: Growth rate of Acropora muricata coral fragments transplanted on dome-shaped concrete artificial reef with different compositions. Biodiversitas 20 (6): 1555-1559. 
Ng CSL, Lim SC, Ong JY, Teo LMS, Chou LM, Chua KE, Tan KS. 2015. Enhancing the biodiversity of coastal defense structures: transplantation of nursery-reared reef biota onto intertidal seawalls. Ecol Eng 82: 480-486.

Ng CSL, TC, Chou LM. 2016. Coral restoration in Singapore's sedimentchallenged sea. Reg Stud Mar Sci 8 (3): 422-429.

Nithyanandan M, Le Vay L, Raja DK, Kesavan R, Pereira D. 2018. Coral nursery and transplantation of the staghorn coral, Acropora downing in Sabah Al-Ahmad Sea City, Kuwait, Arabian Gulf. Cogent Environ Sci 4: 1480334. DOI: 10.1080/23311843.2018.1480334.

Okubo N, Taniguchi H, Motokawa T. 2005. Successful methods for transplanting fragments of Acropora formosa and Acropora hyacinthus. Coral Reefs 24: 333-342.

Sabater MG, Yap HT. 2002. Growth and survival of coral transplants with and without electrochemical deposition of $\mathrm{CaCO}_{3}$. J Exp Mar Biol Ecol 272 (2): 131-146.

Schopmeyer SA, Lirman D, Bartels E, Gilliam DS, Goergen EA, Griffin SP, Johnson ME, Lustic C, Maxwell K, Walter CS. 2017. Regiona restoration benchmarks for Acropora cervicornis. Coral Reefs 36: 1047-1057.
Veron JEN, Stafford-Smith M. 2000. Corals of the world. Australian Institute of Marine Science, Townsville MC, Qld, Australia.

Wilkinson CR. 2000. Executive summary. In: Wilkinson CR (ed.) Status of coral reefs of the world. Australian Institute of Marine Science, Townsville, Australia.

Williams DE, Miller MW. 2010. Stabilization of fragments to enhance asexual recruitment in Acropora palmata, a threatened Caribbean coral. Restor Ecol 18 (S2): 446-451.

Yap HT. 2000. The case for restoration of tropical coastal ecosystems. Ocean Coast Manag 43: 841-851.

Yap HT. 2004. Differential survival of coral transplants on various substrates under elevated water temperatures. Mar Pollut Bull 49: 306-312.

Yap HT, Aliño PM, Gomez ED. 1992. Trends in growth and mortality of three coral species (Anthozoa: Scleractinia), including effects of transplantation. Mar Ecol Prog Ser 83: 91-101.

Young C, Schopmeyer S, Lirman D. 2012. A review of reef restoration and coral propagation using the threatened genus Acropora in the Caribbean and Western Atlantic. Bull Mar Sci 88: 1075-1098. 